\title{
The Job Involvement Construct and its Measurement
}

\section{Hoole and A B Boshoff}

Graduate School of Business, University of Pretoria

\section{ABSTRACT}

Job involvement is an important construct from both the individual and organizsational perspective and has therefore received considerable attention from researchers over the last three decades. Numerous definitions of job involvement exist and it is still not clear of what job involvement is and how it should be viewed, despite the multitute of studies investigating job involvement. Under these circumstances, the focus of the paper is on a review of job involvement, its conceptualisation and measurement. The literature is reviewed, main streams of thought are identified and recommendations for research are stated.

Job involvement is an important construct from both the individual and organizational perspective. From the individual perspective job involvement has been linked to other key concepts such as job satisfaction and to job-related actions such as expenditure of effort and intention to quit. From the organizational perspective, job involvement has been considered as an important activator of employee motivation (Lawler, 1986; Pfeffer, 1994). Job involvement has therefore received considerable attention from researchers over the last three decades.

Several definitions of job involvement were developed before 1980. Allport (1943) stated that job involvement is defined in terms of the degree to which employees are participating in their jobs, meeting needs such as prestige and autonomy. Wickert (1951) and Bass (1965) supported this view. Dubin (1956) defined job involvement as the degree to which the job situation is a central life-interest, that is, where the individual perceives his job, rather than non-job activities, as the main source for the satisfaction of important needs. This was similar to the views of Lodahl and Kejner (1965) and later Lawler and Hall (1970), who defined job involvement as the degree to which the satisfaction derived from a job is central to the person and his psychological identity. Gurin, Veroff and Feld (1960) and 
French and Kahn (1962) defined job involvement as the degree to which an employee perceives job performance as central to his self-esteem. Other terms which have been used in almost synonymous fashion with job involvement are egoinvolvement performance (Vroom, 1962), intrinsic motivation (Lawler and Hall, 1970) and Protestant Work Ethic (Weber, 1947).

A review of the literature seems to indicate that the main stream of research in the job involvement field has been derived from the work of Lodahl and Kejner (1965) and Kanungo (1982) and the measuring instruments developed by these researchers. Although other job involvement instruments were developed and several other definitions of job involvement have been offered, the Lodahl and Kejner (1965) and Kanungo (1982) instruments have been the most widely used (and also criticised).

According to Morrow (1983) job involvement should be seen as one of the facets of work commitment. Morrow (1983) stated that the literature regarding job involvement is ambiguous, resulting in inconclusive findings and inconsistent measuring of job involvement. In an update of the work commitment literature, Morrow (1993) also reviewed other related concepts of job involvement such as specialized commitment as defined by Jans (1985) and job commitment developed by Farrell and Rusbult (1981). Her conclusions imply that the job involvement construct should be seen as a wider construct than had been the case previously.

A lack of clarity on what job involvement is and how it should be viewed from the perspective of it being part of the work commitment construct, appeared to exist. However, Morrow (1993) concluded that it should be seen as a non-redundant facet of the work commitment construct.

Under these circumstances it was decided that a review of the construct and its measurement should be undertaken. The focus of this paper is therefore on job involvement, its conceptualisation and measurement.

\section{EARLY CONCEPTUALISATION AND OPERATIONALISATION OF THE CONSTRUCT}

Lodahl and Kejner (1965) were the first to attempt to define job involvement precisely and to develop an instrument to operationalise the construct. They defined job involvement as "the degree to which a person is identified 
psychologically with his work" and as "the degree to which a person's work performance affects his self-esteem" (Lodahl and Kejner, 1965:25).

Lodahl and Kejner (1965) developed a 20-item scale to measure job involvement as defined by themselves. They originally assembled 110 statements from interview protocols, existing questionnaires, other researchers and self-composed items. All duplicate items were eliminated until 87 items remained. Judges, who were asked to rate each item on a scale of one to eleven (one representing a very low degree of job involvement and eleven representing a very high), reviewed the items. Fortyseven items were eliminated as a result of this process. The remaining forty items were cast into a four point Likert scale and distributed among 137 nursing employees. A total job involvement score was calculated for each respondent. The total score and the data from the 40 items were intercorrelated and factor analyzed. Lodahl and Kejner (1965) extracted seven factors (using Varimax rotation) containing at least more than two items each loading .30 or higher. The seven factors accounted for $77 \%$ of the commonality. The last two factors had zero loadings for the total job involvement score and, consequently they were not interpreted.

The items were further reduced to 20 , based on the item-total correlations, the commonality of an item and the factorial clarity of the item. The items were then administered to a sample of engineers $(\mathrm{N}=70)$. For comparison purposes, the responses to the final 20 items were rescored for the nurses. The total and item scores were then intercorrelated and factor analysed. Lodahl and Kejner (1965) found in both samples that the most variance in the total job involvement score appeared on the first axis (.99 for the nurses and .96 for the engineers respectively), indicating a general job involvement factor. However, for the nurses only six items had their highest loadings on this general factor and for the engineers eleven items. More factors were extracted and a three factor solution was preferred for the data obtained from the nurses and a four factor solution for the responses of the engineers. The first two factors were very similar (although the second and third factor for the engineer sample had opposite signs). The first factor was interpreted as high job involvement, the second factor as an indifferent response to work, and the third factor as the "rejection of extra duties and of the general notion of work as a measure of self" (Lodahl and Kejner, 1965:30). The fourth factor for the engineers seemed to deal with boredom and the unimportance of work.

Lodahl and Kejner (1965) considered their scale to have adequate reliability (corrected split-half correlations for the total scale in different samples ranged between .72 and .89 ) with some discriminant ability. They further stated that job 
involvement was multidimensional and probably not a very internally consistent attitude.

\section{LATER CONCEPTUALISATIONS AND OPERATIONALISATIONS OF THE CONSTRUCT}

Kanungo (1982) stated that the main cause of conceptual ambiguity regarding the definition of job involvement, is the excess meaning attached to the construct. As a result, the measurement instruments lack construct validity. According to Kanungo (1982), the excess meaning of job involvement can be seen in past conceptualizations. Job involvement was, according to him, confused with intrinsic motivation, the antecedent conditions with the state of job involvement and its subsequent effects and the terms work and job were used interchangeably (Kanungo, 1982:341).

In an attempt to try and diminish the previous shortcomings in the conceptualisation of job involvement, Kanungo defined job involvement as the degree to which one psychologically identifies with one's job, that is, a cognitive or belief state of psychological identification with a particular job (Kanungo, 1982:342). He further argued that a person's psychological identification with the job depends on both need saliency and perceptions about the job's potential for satisfying the salient needs.

Kanungo (1982) made a very important distinction between work and job involvement. He stated that, due to the conceptual confusion between work centrality and job involvement evident in the literature, instruments designed to measure these constructs suffer from construct validity problems. Later researchers agreed with this view. Pauley, Alliger and Stone-Ramero (1994) indicated that some instruments measure involvement with the present job, others involvement with work in general but most measure both of these constructs without distinguishing between the two (e.g. measures developed by Lodahl and Kejner, 1965; Saleh and Hosek, 1976). Some of the items in the Lodahl and Kejner (1965) scale clearly illustrate this. Items such as "I live, eat, breathe my job" refer to the importance of a job while other items such as "Most things in life are more important than work" refer to the importance of work in general (Paulley, Alliger and Stone-Ramero, 1994). Work involvement is seen as a relatively enduring belief about the value of work in one's life, transcending a specific job (Kanungo, 1982) and involving psychological identification and engagement with one's career or work in general. Job involvement should be seen as including the worker's psychological identification with a specific job context (Blau, 1985; Kanungo, 
1982). Evidence for the distinction between job and work involvement was obtained when Kanungo (1982:344) found two clearly separate factors when the items in his job and work involvement scales were factor analysed together.

However, the independence of the Kanungo (1982) work involvement scale has been doubted (Blau, 1985; Morrow, 1993; Hoole, 1997). It has been suggested that the Protestant Work Ethic developed by Blood (1969) and Kanungo's (1982) work involvement scale, measures the same concept namely a general work ethic. Empirical findings by Blau, Paul and St. John (1993) and Hoole (1997) seem to support this view.

Kanungo (1982) proposed a ten-item measure of job involvement which he felt was more representative of the psychological identification conceptualisation of job involvement. Kanungo's (1982) scale built on Lodahl and Kejner's (1965) work and included four of the items of the original scale that appeared to tap the "psychological identification" dimension unambiguously (Kaplan, 1990:78).

Kanungo seems to have eliminated several dimensions of excess meaning which was encountered in the Lodahl and Kejner (1965) scale such as the mixing of items tapping cognitive and affective states, the individual's involvement in work in general and in a specific job, and intrinsic motivation as well as job involvement (Brown, 1996:236). Kanungo's (1982) scale can be considered as a refined form of the Lodahl and Kejner (1965) scale.

Kanungo (1982) used three different measurement formats in the development of his job involvement scale namely a questionnaire, semantic differential and a graphic technique. Questionnaire items that reflected a cognitive state of psychological identification with one's job were judged by 10 graduate students. There was complete agreement on 12 items. Based on subsequent item analyses, two of these items were not included in the final scale. For the semantic differential scale, six graduate students identified 11 bipolar items (using available literature and dictionaries for synonyms and antonyms) on which there were total agreement. Three of these items were dropped on the basis of inter-item and item-total correlations. Two graphic items representing psychological identification were selected for the graphic scale. The final instrument was administered to 900 French and English speaking employees who were enrolled for extension courses at three different universities. Seven hundred and three questionnaires were returned. Responses from these were analysed statistically. A parallel study $(\mathrm{N}=63)$ was performed at two of the universities to establish test-retest reliabilities of the 
measures. The questionnaires were in this part of the study administered three weeks apart.

The Alpha coefficients for the three measures of job involvement were .81 (semantic differential), .87 (questionnaire) and .70 (graphic items). The test-retest coefficients were, in the same order, respectively $.74, .85$ and .82 .

After further analysis of his data, Kanungo reported that his job involvement scale had acceptable convergent and discriminant validity. He concluded that job involvement proved to be a unidimensional construct.

\section{EVALUATIVE STUDIES OF THE CONCEPTUALISATIONS AND MEASURING INSTRUMENTS}

Researchers seem to agree that the psychological identification with one's work is part of job involvement (Lawler and Hall, 1970; Saleh and Hosek, 1976) but disagree whether the performance self-esteem element is a dimension of job involvement. The literature indicates a conceptual overlap between performanceself-esteem job involvement and Protestant Work Ethic.

Blau (1985) investigated the possible overlap between intrinsic motivation (as measured by Lawler and Hall (1972)), job involvement as the psychological identification with one's job (as proposed by Kanungo, 1982), and job involvement as proposed by Lodahl and Kejner (1965) where the performance self-esteem contingency and psychological identification dimensions are operationalized. Principal Factor Analysis was carried out on the responses of the participants and a two factor solution was obtained. Blau (1985) found that all Kanungo's items except for the one negatively worded item loaded on one factor. The items of the Lodahl and Kejner (1965) scale were confounded with the intrinsic motivation items. In order to retest his initial findings, Blau (1985) conducted a second study where he investigated the possible overlap among the performance-self-esteem contingency dimension of job involvement (as proposed by French and Kahn, 1962), active participation dimension (developed by Allport, 1943), central lifeinterest dimension (Lawler and Hall, 1970), Protestant Work Ethic (Weber, 1947), skill variety (measured by means of the Job Characteristic Inventory by Sims, Szilagyi \& Keller, 1976), participative leadership (measured by means of the Leader Behaviour Description Questionnaire developed by Hemphill and Coons, 1957) and intrinsic motivation (Lawler, 1969). A series of factor analyses were carried out to determine the discriminant validity of the various dimensions and to 
test their independence. Multiple loading problems were found between the performance-self-esteem job involvement dimension and intrinsic motivation, and between participative leadership and decision influence job involvement items. Blau (1985) reported that only the psychological identification job involvement conceptualization was empirically independent and clearly identifiable.

This result supports the view developed by Brown (1996) that, due to the lack of a clear conceptual definition of job involvement, the Lodahl and Kejner (1965) 20item scale was not developed to operationalise a single clearly defined conceptualisation of the construct.

According to Morrow (1983), this low epistemic correlation (weak link between its conceptual definition as proposed by Lodahl and Kejner (1965) and its operationalisation (Northrop, 1959)) which existed in earlier definitions led to confusion in related research resulting in inconclusive findings and the development of poor measuring instruments. Kaplan (1990:76) suggested that for research to be cumulative and directed, a clear definition and a common purpose are necessary. This is in accordance with the views expressed in this regard by Kerlinger (1986). The Lodahl and Kejner (1965) scale therefore has been the source of some confusion and the cause of some of the lack of progress in this area.

The Lodahl and Kejner (1965) scale has often been under scrutiny and subjected to criticism. According to Rabinowitz and Hall (1977), Lodahl and Kejner never clearly named the dimensions of job involvement (Lodahl and Kejner (1965) never indicated whether they recommended a three or four factor solution). Researchers such as Lefkowitz (1967), Schwyhart and Smith (1972) and Wood (1974), who all used the Lodahl and Kejner scale, offered support for the multidimensional nature of job involvement. In these studies, the scale's factor structure was not stable across different samples. Schwyhart and Smith (1972) found three interpretable factors of which only one factor was similar to the factors found by Lodahl and Kejner (1965). Wood (1974) found five factors using the 20-item scale of Lodahl and Kejner (1965). A possible reason for the factorial instability is the sample size used by Lodahl and Kejner (1965). The generally accepted rule (Kerlinger, 1986) is that the item-respondent ratio must be at least five times the number of respondents to the number of items. The validation sample of Lodahl and Kejner (1965) consisted of 137 nurses and the scale included 40 items which gives an itemrespondent ratio of 1:3.425. The ratio of the second sample (70 engineers and 20 items) was 1:3.5. Factor loadings also tend to be more stable in large samples, for instance 300 or more (Thorndike, 1982). 
According to Morrow (1983), the measures resulting from Lodahl and Kejner's (1965) definition were not deductively formulated in order to operationalise either conceptual notion included in the original definition. They arrived at their measures inductively through factor analytic procedures. The Lodahl and Kejner measures were thus not based on any a priori definition or theoretical framework.

Shortened versions of the Lodahl and Kejner (1965) scale, with six and four items respectively, have often been used in practice (Brown, 1996). The six-item scale was composed by using the six items with the highest loadings on the first factor from the 20-item scale developed by Lodahl and Kejner (1965). Lodahl and Kejner (1965) reported a correlation of .87 between the 20 -item and the six-item scale. The six-item version had in later studies multiple loading problems on psychological identification of job involvement and intrinsic motivation (Cummings and Bigelow, 1976; Lawler and Hall, 1970).

Ramsey, Lassk and Marshall (1995) critically evaluated the use of the Lodahl and Kejner (1965) scales (20-, 6-, and 3-item scales respectively) by means of the LISREL 7 programme (Jöreskog and Sorbom, 1989) on a sample of 290 salespeople employed by an insurance company. The Cronbach Alphas for the three versions were $.79, .70$ and .69 for the 20 -item, 6-item and 4 -item versions respectively. In order to assess the dimensionality of the three scales, the sample was split in halves and the results were cross validated. Hypothesis tests by means of Chi-square for the twenty- and six-item scale led to the rejection of the null hypothesis but the null-hypothesis could not be rejected for the four-item scale. It seemed as if the four-item scale was more representative of a unidimensional construct of job involvement than the other two versions and provided the best fit of the three scales. The fit indices obtained from the subsample were at comparable levels and the scales therefore all appeared to be stable.

In order to assess the validity of the three scales, the correlations among job involvement, job satisfaction, job performance (using the Behrman and Perreault (1982) five-dimension measure of salesperson job performance), motivation and the seven dimensions of a reduced version of the INDSALES scale (Comer, Machleit \& Lagace, 1989) were calculated. The twenty-item job involvement scale was significantly correlated with all seven dimensions of the INDSALES scale. The six-item scale correlated significantly with all the dimensions of the INDSALES scale except satisfaction with co-workers and the four-item scale correlated significantly with all the dimensions with the exception of two dimensions of job satisfaction (i.e. pay and co-workers). None of the job involvement scales correlated significantly with the job performance dimension of 
providing input to the company. However, the twenty-item job involvement scale correlated significantly positively with three dimensions of the job performance scale i.e. meeting objectives, technical expertise and controlling expenses. The sixitem scale correlated significantly with four dimensions of job performance i.e. meeting objectives, technical expertise, controlling expenses and customer interaction. The four-item scale correlated significantly with the meeting objectives and customer interaction dimensions of job performance. The six and four-item scales correlated significantly with intrinsic and extrinsic motivation, and the twenty-item scale correlated significantly with intrinsic motivation. The authors did not provide the values of the correlation coefficients. With $\mathrm{N}=290$, a correlation coefficient could be indicating very little common variance and still be statistically significant.

Use of the shorter versions of Lodahl and Kejner's (1965) scale has itself been under attack. Brown (1996) pointed out that the shortened versions of the Lodahl and Kejner (1965) scales were generally used without a rationale being given for deciding which subset of the 20 -item scale to include in the measurement.

Ramsey et al. (1995) concluded that the assessment of the three versions of the Lodahl and Kejner (1965) scale yielded generally acceptable reliabilities, unstable dimensionalities and mixed resuits in terms of validities. They further concluded that although more studies would be needed, the results strongly implied that caution should prevail when the Lodahl and Kejner (1965) scale is used.

Support for Kanungo's (1982) results was offered by several studies (Blau, 1985; Blau, Paul \& St John, 1993; Brooke, Russel \& Price, 1988; Kaplan, 1990; Kamfer and Venter, 1997; Boshoff and Hoole,1998). The reported internal reliabilities for the Kanungo scale are uniformly high, generally above .80. Kaplan (1990) further reported that Kanungo's (1982) job involvement scale's factor structure seemed to be stable across samples and even cultures. Similar factor structures were obtained using French and English Canadian employees (Kanungo, 1982), American nurses and several categories of university employees (Blau, 1985) and English and Afrikaans South African professionals (Boshoff, Bennett \& Kellerman, 1994; Kamfer and Venter, 1997; Kaplan, 1990). In her review of work commitment measures (Morrow, 1993) reported that over 11 studies, with one exception, Cronbach Alpha estimates for Kanungo's scale have met or exceeded .70. The testretest estimates of .63 (Blau, 1985) over seven months are somewhat lower but consistent with the assumption that job involvement is subject to job situation changes. 
Some studies reported that one of the items (Item 7) made a poor contribution to the job involvement scale (Paterson and O'Driscoll, 1990; Blau, 1985). Blau et al. (1993) reported that items 3,6 , and 7 respectively exhibited multiple loading problems in their study.

Kanungo's work was further criticized for the fact that his sample consisted of mainly educated people (Patterson and O' Driscoll, 1990; Paulley, Alliger \& StoneRamero, 1994). Paulley et al. (1994) further argued that the theory behind Kanungo's framework that job involvement is the cognitive aspect of job satisfaction, was somewhat problematic and that his results pointed to a redundancy possibility between job involvement and job satisfaction rather than the distinction between the two constructs. Patterson and $O^{\prime}$ Driscoll (1990) also considered that Kanungo's study did not offer sufficient information on the criterion validity of the scale. In order to address some of these limitations, Patterson and $O$ 'Driscoll (1990) conducted a study where Kanungo's (1982) job involvement scale was empirically assessed. Their sample consisted of 157 full-time workers from 32 New Zealand organizations. Individuals with formal qualifications were, unfortunately, again over represented in their sample. Removal of the negative worded item in the scale improved the Alphas from .83 to .86 and the test-retest coefficients from .87 to .88 . When the two educational groups (low versus high) were compared with each other, the biggest improvement in eliminating the negative worded item was in the low educational group. The value for Cronbach's Alpha improved from .86 to .89 for the lower educational group at the two test periods but little difference was seen in the case of the high educational group. This seems to indicate that the negative worded item is not portable across different and diverse samples, as Blau (1985) suggested.

The results of the Patterson and O'Driscoll (1990) study also offered some support for the criterion validity of Kanungo's (1981) job involvement scale. Job involvement was in this study related to job satisfaction (.32 and .39 at time 1 and time 2 respectively) and job preference (.38 and .43 at time 1 and time 2 respectively) as well as to numbers of hours worked weekly (.34 and .35 ), amount of unpaid overtime worked $(.20$ and .27$)$ and effort put into the job (.34 at both time intervals).

Studies of Kanungo's (1982) scale have therefore shown this instrument to be superior to previous measures of job involvement (Blau, 1985; Boshoff and Bennett, 1991; Morrow, 1993; Paterson and O'Driscoll, 1990; Paulley, Alliger \& Stone-Ramero, 1994). 
The conceptualisation of job involvement has therefore received several questions, especially regarding the conceptual ambiguity and operational multidimensionality of the Lodahl and Kejner (1965) scale. Different versions of the scales have been used without a proper rationale for using certain subsets of the scales. The results of studies on the Kanungo (1982) job involvement scale generally presented a more favourable picture of the representativeness of the items in the scale of the construct as seen by the author of the instrument.

A meta analysis carried out by Brown (1996) which included data from 212 studies provided the opportunity to assess the effect of using the different job involvement scales on the magnitude of relationships among scores on the instruments and other variables. Results from Brown's (1996) study indicated that the concern regarding the conceptual and measurement issues in the job involvement literature was somewhat overstated. When, for instance, results from various versions of the Lodahl and Kejner (1965) scale were compared with results obtained with the Kanungo (1982) scale, very little effect of measure was evident. Only for the relationships between job involvement and role perceptions did the use of the Lodahl and Kejner (1965) versus Kanungo (1982) scale influence the strength of the relationship. Brown (1996) found no significant difference in any relationships between the mean correlation for all studies that used some version of the Lodahl and Kejner scale and those that used the Kanungo scale.

The results obtained by Brown (1996) suggested that the two scales measure the same phenomenon and have approximately equal empirical validity with regard to a range of related variables.

In the first phase of a large study on work commitment conducted by Boshoff, Hoole, Bennett and Jillings (1997), the Lodahl and Kejner (1965) and Kanungo (1982) scales were combined in order to determine the underlying dimension of the job involvement facet. The sample consisted of 1019 South African respondents from approximately 50 organisations. Exploratory and Confirmatory Factor analysis were conducted using the BMDP (1993) and SAS (1994) statistical analysis programme. All items not loading .30 and cross loading on more than one factor were eliminated. A one factor structure seemed to provide the best solution.

The newly constructed scale consisted of 22 items. Eight items originally included in the scales were therefore eliminated. In order to revalidate the job involvement scale in a South African context the job involvement facet, amongst the other work commitment facets, were psychometrically and factorially investigated in a further study (Hoole, 1997). The second sample consisted of 1527 members of a large 
financial service company and a university. The sample was for the purpose of the analyses divided into several subgroups, i.e. the financial institution, academic, university administrative and total university employees subgroups.

The responses to the 22 job involvement items were again subjected to Exploratory and Confirmatory Factor Analysis. An oblique rotation of axes (Direct Quatermin) was utilised as it was thought unlikely that the dimensions measured would be independent from each other. A one and a two factor solution were specified. The one factor solution explained $32.32 \%$ of the total variance and had an Alpha coefficient of .902 . The Alpha coefficients of the two factor solution were .886 and .772 respectively. The two factors explained $31.26 \%$ and $7.44 \%$ of the total variance. Confirmatory Factor Analysis was carried out to determine which solution provided the best fit. The fit indices showed that the one factor solution was to be preferred. The same procedures were carried out for the various subgroups of the sample and very similar results were obtained. The one factor structure seemed to provide the best solution for the financial, university administrative and the total university subgroups.

Although the one factor solution provided the best solution in terms of fit indices and amount of explained variance, the two factor solution was somewhat easier to interpret. A scrutiny of the items in the one factor solution suggests that the problem of interpretation is due to the referents used. In the case of the job involvement items obtained from the scale developed by Lodahl and Kejner (1965) the work and job terms were used interchangeably. Kanungo (1982) made a very clear distinction between work and job involvement. Refinement of the items so that only one referent is used would certainly increase the interpretability of the scale. These findings also suggest that job involvement is a broader concept than measured by Kanungo's (1982) scale.

\section{CONCLUSION}

In the light of the various results discussed in this paper, it seems as if the conceptual confusion in the job involvement literature might be coming to an end although more work needs to be done. The meta-analytical study conducted by Brown (1996) provided some valuable insight into the real significance of reported relationships in the past. It seems to be clear that job involvement as measured by the currently available instruments tends to be unidimensional, but that more attention must be given to the referent problem. There seems to be general 
acceptance that job involvement can be defined as the psychological identification with one's job as proposed by Kanungo (1982).

In terms of the measurement of job involvement, the psychometric qualities of the unidimensional scale resulting from the Boshoff et al. (1997) study are at acceptable levels. For future research purposes it would be beneficial to revise the wording of some of the items of the newly combined scale of Lodahl and Kejner (1965) and Kanungo (1982) that emerged out of the studies conducted by Boshoff, Hoole, Bennett, and Jillings (1997) and Hoole (1997).

It is recommended that the job involvement concept be examined in other than Westem (e.g. African and Eastern) cultures in order to further investigate the portability of the job involvement construct as it is currently defined and the content of the concept in different cultures.

The one question that remains is whether the contents of the phenomenon are adequately covered by the currently available instruments and the conceptualisations on which they are based. This review indicated that the currently available scales, especially the one developed by Kanungo (1982), seem to be psychometrically acceptable. This obviously does not mean that the scales encompass all the elements of the phenomenon which is to be measured. It seems as if it may be profitable to examine the job involvement concept further, using data gathering methods other than questionnaires, in an exploratory fashion. A study in which individuals from different cultures, organisations, occupations and jobs are interviewed (and data gathered in other ways) in order to determine the elements which are capable of making them involved with a job or reduces involvement with a job, is envisaged. This seems to be especially important in the light of change which are taking place in the nature of work, careers and in organisations. It seems doubtful that job involvement can still be seen as the same phenomenon with the same content as a decade and a half ago. In terms of measuring instruments, the question therefore is: Are we still asking the right questions? 


\section{REFERENCES}

1. ALLPORT, G.W. (1943). The Ego in Contemporary Psychology. Psychological Review, 50, 451-476.

2. BASS, B.M. (1965). Organizational Psychology. Boston: Allyn and Bacon,

3. BEHRMAN, D.N. \& PERREAULT, W.D. (1982). Measuring the Performance of Industrial Salespersons. Journal of Business Research, 10, 355-370.

4. BENTLER, P.M. (1980). Multivariate Analysis with Latent Variables: Causal Modeling. Annual Review of Psychology, 31, 419-456.

5. BLAU, G.J. (1985). A Multiple Study Investigation of the Dimensionality of Job Involvement. Journal of Vocational Behavior, 27, 19-36.

6. BLAU, G.J. (1989). Testing the Generalizability of a Career Commitment Measure and its Impact on Employee Turnover. Journal of Vocational Behavior, 35, 88-103.

7. BLAU, G.J., Paul, A., \& St. John, N. (1993). On Developing a General Index of Work Commitment. Journal of Vocational Behavior, 42, 298-314.

8. BLOOD, M.R. (1969). Work Values and Job Satisfaction. Journal of Applied Psychology, 53, 456-459.

9. BOSHOFF, A.B., \& BENNETT, H.F. (1991). Job Involvement and Job Satisfaction of South African Psychologist and some 1mplications for the Quality of Life of Members of the Profession. Paper presented at the PASA annual conference, September 1991.

10. BOSHOFF, A.B., \& BENNETT, H.F. \& KELLERMAN, A.M. (1994). Prediction of Job Involvement of Professionals by Means of Career Orientation Scores. Journal of Industrial Psychology, 20(2), 8-13.

11. BOSHOFF, A.B. \& HOOLE, C. (1998). Portability of the Job Involvement and Job Satisfaction Constructs between the United States of America and South Africa. South African Journal of Economic and Management Sciences, 1, 73-84.

12. BOSHOFF, A.B., HOOLE, C., BENNETT, H.F. \& JILLINGS, R. (1997). Study of Work. Unpublished Data: University of Pretoria and Massey University.

13. BROOKE, P.P., RUSSELL J.D.W. \& PRICE, J.C. (1988). Discriminant Validation of Measures of Job Satisfaction, Job Involvement and Organizational Commitment. Journal of Applied Psychology, 73, 139-145.

14. BROWN, S.P. (1996). A Meta-Analysis and Review of Organizational Research on Job Involvement. Psychological Bulletin, 120(2), 235-255. 
15. COMER, J.M., MACHLEIT, K.A. \& LAGACE, R.R. (1989. Psychometric Assessment of a Reduced Version of INDSALES. Journal of Business Research, 18, 291-302.

16. CUMMINGS, T. \& BIGELOW, J. (1976). Satisfaction, Job Involvement and Intrinsic Motivation: An Extension of Lawler and Hall's Factor Analysis. Journal of Applied Psychology, 61, 523-525.

17. DUBIN, R. (1956). Industrial Workers' World, A Study of the 'Central Life Interests' of Industrial Workers. Social Problems, 3, 131-142.

18. FARRELL, D. \& RUSBULT, C.E. (1981). Exchange Variables as Predictors of Job Satisfaction, Job Commitment and Turnover, The Impact of Rewards, Costs, Alternatives, and Investments. Organizational Behavior and Human Performance, 27, 78-95.

19. FRENCH, J.R. JR. \& KAHN, R. (1962). A Programmatic Approach to Studying the Industrial Environment and Mental Health. Journal of Social Issues, 18, 1-47.

20. GURIN, G., VEROFF, J., \& FELD, S. (1960). Americans View Their Mental health. New York: Basic books.

21. HEMPHILL, J. \& COONS, A. (1957). Development of the Leader Behavior Description Questionnaire. In R. Stogdill \& A Coons (Eds.), Leader Behavior: Its Description and measurement. Columbus: Ohio State University.

22. HOOLE, C. (1997). Biographic Questionnaire. PhD Disseration: University of Pretoria.

23. JÖRESKOG, K.G. \& SORBOM, D. (1989). LISREL7: A Guide to the Programme and Applications ( ${ }^{\text {nd }}$ ed.). Chicago: SPSS.

24. KAMFER, L. \& VENTER, D.J.L. (1997). The Portability of American Job Involvement and Job Satisfaction Scales to Non-English Speaking South Africans. Paper presented at the Fourth Annual International Conference on Advances in Management, Toronto, 9-12 July.

25. KANUNGO, R.N. (1982). Measurement of Job and Work Involvement. Journal of Applied Psychology, 67, 341-349.

26. KAPLAN, R.A.L. (1990). The Career Anchors Job Involvement and Job Satisfaction of Professional People. Doctoral Dissertation. University of Cape Town.

27. KERLINGER, F.N. (1986). Foundations of Behavioural Research (3 $3^{\text {rd }} \mathrm{ed}$.). NY: Holt: Rinehart and Winston, Inc.

28. LAWLER, E.E. (I969). Job Design and Employee Motivation. Personnel Psychology, 22, 426-435. 
29. LAWLER, E.E. (1986). High-Involvement Management: Participate Strategies for Improving Organizational Performance. San Francisco: Jossey Bass Publishers.

30. LAWLER, E.E., \& HALL, D.T. (1970). Relationships of Job Characteristics To Whom It May Concern: Job Involvement, Satisfaction, and Intrinsic Motivation. Journal of Applied Psychology, 54, 305-312.

31. LEFKOWITZ, J. (1967). Self-esteem of Industrial Workers. Journal of Applied Psychology, 51, 521-528.

32. LODAHL, T., \& KEJNER, M. (1965). The Definition and Measurement of Job Involvement. Journal of Applied Psychology, 49, 24-33.

33. MORROW, P.C. (1983). Concept Redundancy in Organizational Research: The Case of Work Commitment. Academy of Management Review, 8, 486500 .

34. MORROW, P.C. (1993). The Theory and Measurement of Work Commitment. Greenwich, England. JAI Press.

35. MORROW, P.C., EASTMAN, K., \& MCELROY, J.A. (1991). Concept Redundancy and Rater Naivety in Organizational Research. Journal of Applied Social Psychology, 21, 219-232.

36. NORTHROP, F.S.C. (1959). The Logic of Modern Physics. New York: Macmillan.

37. PATERSON, J.M. \& O'DRISCOLL, M.P. (1990). An Empirical Assessment of Kanungo's (1982) Concept and Measure of Job Involvement. Applied Psychology: An International Review, 39, 293-306.

38. PAULlay, I.M., ALLIGER, G.M. \& STONE-ROMERA, F. (1994). Construct Validation of Two Instruments Designed to Measure Job Involvement and Work Centrality. Journal of Applied Psychology, 79(2), 224-228.

39. RABINOWITZ, S. \& HALL, D.T. (1977). Organizational Research on Job Involvement. Psychological Bulletin, 84(2), 265-288.

40. RAMSEY, R., LASSK, F.G. \& MARSHALL, G.W. (1995). A Critical Evaluation of a Measure of Job Involvement: The Use of the Lodahl and Kejner (1965) scale with salespeople. Journal of Personnel Selling and Sales Management, 315(3), 65-74.

41. SALEH, S.D. \& HOSEK, J. (1976). Job Involvement: Concepts and Measurements. Academy of Management Journal,_19(2), 213-224.

42. SCHWYHART, W.R. \& SMITH, P.C. (1972). Factors in the Job Involvement of Middle Managers. Journal of Applied Psychology, 56, 227233. 
43. SIMS, H., SZILAGYI, A. \& KELLER, R. (1976). The Measurement of Job Characteristics. Academy of Management Journal, 19, 195-212.

44. THORNDIKE, R.L. (1982). Applied Psychometrics. Boston: Mifflin.

45. VROOM, V.H. (1962). Ego-involvement, Job Satisfaction, and Job Performance. Personnel Psychology, 15, 159-777.

46. WEBER, M. (1947). The Theory of Social and Economic Organization. New York: Oxford University Press.

47. WEBER, M. (1958). The Protestant Ethic and the Spirit of Capitalism. New York: Charles Schriber's Sons.

48. WICKERT, F.R. (1951). Turnover, and Employees' Feelings of EgoInvolvement, in the Day-to-Day Operations of a Company. Personnel Psychology, 4, 185-197.

49. WOOD, D.A. (1974). Effect of Worker Orientation Differences on Job Attitude Correlates. 